\title{
Prevalence of mental health problems among children and adolescents in Germany: results of the BELLA study within the National Health Interview and Examination Survey
}

\author{
Ulrike Ravens-Sieberer, Nora Wille, Michael Erhart, Susanne Bettge, Hans-Ulrich Wittchen, \\ Aribert Rothenberger, Beate Herpertz-Dahlmann, Franz Resch, Heike Hölling, Monika \\ Bullinger, Claus Barkmann, Michael Schulte-Markwort, Manfred Döpfner
}

as the BELLA study group

\begin{abstract}
Background Over the past decades the public health relevance of mental health conditions in children and adolescents has been of growing concern. However, so far no detailed epidemiological data has been available for a representative national sample in Germany.

Objectives The present paper reports prevalence rates of general and specific mental health problems among children and adolescents in Germany and describes the link between symptoms and impairment as well as the treatment situation.

Methods The mental health module (BELLA study) examines mental health problems in a representative sub-sample of 2,863 families with children aged 7-17 from the National Health Interview and Examination Survey among Children and Adolescents (KiGGS). Mental health problems were determined using the extended version of the strengths and difficulties questionnaire (SDQ). Further standardised screening measures were employed to screen for anxiety disorders (SCARED), conduct disorder (CBCL), attention deficit-/ hyperactivity disorder (FBBHKS, Conners' Scale) and depressive disorders (CES-DC). Furthermore, substance abuse and suicidal tendencies were assessed. Health-related quality of life (HRQoL) and health care use were determined. Results Overall, $14.5 \%$ of the children and adolescents aged $7-17$ fulfilled the criteria for at least one specific mental health problem associated with impairment, or had an overall mental health problem indicated by an abnormal SDQ score and present impairment. However, high comorbidity was found in the children concerned. Symptoms of overall mental health problems were present in $8.6 \%$ of the children and $6.6 \%$ of the adolescents. This number was reduced to prevalence rates of 6.3 and $4.9 \%$ when additional impairment was taken as a criterion. Irrespective of the type of disorder, fewer than half of the children affected were reported as receiving treatment. However, for those suffering from mental health problems, large impairments in HRQoL were observed.

Conclusions The observed prevalence of mental health problems as well as their large impact on wellbeing and functioning calls for early prevention. This is especially important with regard to the large decrease in HRQoL in the children and adolescents affected.
\end{abstract}

Key words mental health survey, children and adolescents, mental disorder, screening, health-related quality of life

\section{Introduction}

Within the last century, considerable changes in the health and illness pattern of children and adolescents have been observed. One characteristic of this phenomenon, which is referred to as the 'new morbidity' or even the 'millennial morbidity', is the growing importance of mental health concerns [33]. Emotional and conduct problems are observed in about 10-20\% of the children and adolescents $[9,43]$. International findings result in a median of $12 \%$ across different studies [17]. These problems are often a great burden to the individual and limit e.g. school functioning and well-being, or social relationships in the family and with friends [34]. 
Furthermore, mental health problems are highly persistent [29]. Thus, a large proportion of the children and adolescents concerned can be assumed to be affected also in adulthood [17, 34].

Against this background, the availability of comprehensive information regarding the prevalence of mental disorders in children and adolescents is of great importance. In addition to knowledge regarding overall mental health, detailed information about the kinds of mental health problems and their distribution is essential. Furthermore, the question must be considered in which way and how strongly children and adolescents with mental health problems are limited in their everyday functioning and their health-related quality of life (HRQoL). Beyond this description of present mental health problems, the actual health care situation of the children and adolescents needs to be examined.

Achieving valid and reliable information about the prevalence of mental health problems and disorders is associated with methodological challenges [17, 38]. Referring to data on the health care utilisation of corresponding treatments leads to an underestimation of prevalence, since in many cases mental health problems fail to be diagnosed or are misdiagnosed [6]. The best basis for prevalence estimates are diagnoses using the ICD-10 or DSM-IV classification systems and made by a clinician in a representative sample. In practice, however, less costand time-consuming methods are used, drawing on different sources of information. Epidemiological studies, in particular, often apply screening instruments, which assess the occurrence of symptoms and burden. From the answers to a set of questions, they infer the probability of a particular mental disorder or of mental health problems in general.

Not surprisingly, the prevalence estimates from international studies differ widely $[17,29,38]$ though one review indicates that three quarters of the studies found rates between 15 and 22\% [29]. The median value of published prevalence estimates is reported to be $18 \%[29,38]$ or $12 \%$ regarding serious emotional disturbance [17]. Similar rates have been reported for Germany $[7,18]$, even though a large variation was observed, too. In a recent review, Barkmann and Schulte-Markwort [8] identified 29 studies on the prevalence of mental health problems, with a mean prevalence of $17.2 \%$ and estimates ranging between 10 and $30 \%$. However, despite the fact that studies find very different estimates, it can be concluded in summary that a sizeable proportion of children and adolescents are consistently classified as displaying noticeable mental health problems.

Within the BELLA study, a representative national sample of children and adolescents was surveyed and comprehensive information on the occurrence, severity and impact of manifold symptoms of mental health problems was collected from the children themselves and their parents. Furthermore, potential risk factors and resources $[5,31]$ were assessed as well as HRQoL. In addition, the parents reported whether their child needed or received treatment for mental health problems. The BELLA study has the potential to add to the current understanding of mental health problems in children and adolescents with regards to their prevalence and their consequences.

The main questions to be answered in the present paper concern the following aspects:

1. Which prevalence rates of overall and specific mental health problems are found by means of the chosen screening instruments using their published cut-off scores?

2. How many of the children identified were actually impaired by reported symptoms of mental health problems and can therefore be considered as cases?

3. In how many of the children identified was the need for treatment recognised or realised? 


\section{Methods}

\section{Study design, recruitment and sample}

The BELLA study is an extension (Mental Health Module) of the National Health Interview and Examination Survey for Children and Adolescents (KiGGS) that was conducted from May 2003 to May 2006 in Germany by the Robert Koch-Institute. This nationwide survey examined the health status of 17,641 children and adolescents aged 0 to 17 years. Subject recruitment was carried out by first choosing 167 study locations throughout Germany and then selecting potential study participants from the official registers of the local residents' registration offices. The chosen subjects were invited to take part in the survey, which included a physical examination, various tests, questionnaires and a computer-assisted personal interview. The examination took place in an examination room in the city or municipality where the participants lived and was conducted by a professional team including a physician and other professionals. The survey achieved a participation rate of $66.6 \%$ and included a representative sample of 17,641 children and adolescents. Non-responder analysis showed no significant differences between responders and non-responders regarding healthrelated characteristics. A detailed description of sample design and response has been published elsewhere [30].

In association with the National Health Interview and Examination Survey for Children and Adolescents (KiGGS), the BELLA study collected more detailed data on mental health in a representative subsample of 2,863 families with children aged 7-17 [36].

A random selection of 4,199 families from the KiGGS sample with children aged 7-17 was asked to participate in the BELLA study. Of these eligible families, $70 \%(n=2,942)$ agreed to participate. Of those who gave their consent, $97 \%$ took part in the study $(n=2,863)$.

In each family participating in the BELLA study, one computer-assisted telephone interview was conducted with the child and one with a parent. Afterwards, a questionnaire was sent to the participating family. In families with children aged 7-10 only the parent was interviewed by telephone and questionnaire.

In order to ensure representativeness of the data presented, analyses were conducted using a weighting factor which adjusted for differences between the study sample and the German population regarding age, gender, geographical region and citizenship (reference data 31 Dec 2004).

Since it was not possible to conduct the data collection in different languages, migrants were only able to participate if they were sufficiently proficient in the German language. Therefore, the migrants included in the sample cannot be considered to be representative of the migrant population in Germany. Thus, differentiated analyses regarding the migrant status were not conducted.

\section{Instruments}

All the instruments applied were tested in the survey pretest and proved to be sufficiently reliable and valid instruments $[11,12]$. Overall mental health problems were assessed using the extended version of the SDQ [24, 25]. Specific mental health problems were identified using standardised screening instruments that were constructed taking into account diagnostic 
criteria (such as ICD-10 or DSM-IV). To ensure comparability of the results across age groups, only parent-reported data are considered since these are available for both age groups.

\section{Mental health problems: strengths and difficulties questionnaire}

To screen for mental health problems in general, the SDQ was administered in children as well as in parents. Positive and negative attributes are assessed using 25 items referring to the past 6 months (with $0=$ not true, $1=$ somewhat true, $2=$ certainly true) comprising the following dimensions: emotional problems, conduct problems, hyperactivity/inattention, peer relationship problems and prosocial behaviour. Each of the 25 items on the SDQ is scored on a 3-point scale, with higher scores indicating larger problems. Items of the four problem areas are summed up to generate a total difficulties score $(0-40)$. The sub-scores of the four difficulties dimensions range from 0 to 10 [24]. Based on a large representative sample of the United Kingdom, cut-off points were defined classifying the test results into normal, borderline and abnormal mental health problem scores [32]. In order to provide a conservative prevalence estimate, only young people with 'abnormal' SDQ scores were considered to have mental health problems.

\section{Perceived difficulties: SDQ-Impact}

The BELLA study permits a more precise detection of mental health problems by additionally administering the SDQ impact supplement [25] which especially covers the aspect of impairment by the given symptoms. This extension of the SDQ was administered in the BELLA self-report as well as in the BELLA parent-reported questionnaire, and asks the respondent if difficulties regarding emotions, concentration, behaviour or getting on with other people are present. If so, associated chronicity, distress, social impairment and burden to others are further examined. The impact score was calculated by adding up the distress items and the social incapacity items using the 0012' scoring [25] which disregards reports of smaller levels of distress. Children and adolescents were considered to be impaired when the impact score was 1 or higher.

Goodman [27] provides an algorithm that combines the information from the SDQ total difficulties score and from the SDQ impact supplement of different informants and predicts a psychiatric disorder as being 'unlikely', 'probable', or 'likely'. Results for prevalence rates of mental health problems based on the application of this algorithm have been published elsewhere [37]. In the current paper, we have combined the information from the two parts of the parent-reported SDQ (symptoms and impact) by examining the intersection of children with abnormal symptom scores and associated impairment (impact scores of 1 and higher) in order to investigate the role of symptoms versus impact in the assessment of mental health problems.

\section{Anxiety: SCARED}

Anxiety disorders were identified using the German version of the SCARED questionnaire (Screen for Child Anxiety Related Emotional Disorders) [13, 14]. It was administered during the BELLA telephone interview, both in a self-reported and a parent-reported form. This questionnaire contains 41 items [13] which can be assigned to five subscales according to the factors of the instrument: panic/somatic, generalised anxiety, separation anxiety, social phobia, and school phobia. The present report provides the results of the reduced version with five items, which includes one item for each factor and displays psychometric properties similar to those of the full SCARED [13]. A cut-off score of 3 was used in order to determine 
present anxiety. This cut-off was defined empirically so as to maximise sensitivity and specificity in a clinical sample [13].

\section{Depression: CES-DC}

To identify children with signs of depression, the Center for Epidemiological Studies Depression Scale for Children (CES-DC) [21, 39] was employed.

It was administered as a self-reported and a proxy-reported version in a standardised telephone interview. In each version it contains 20 items referring to the last week that cover positive affect, as well as cognitive, behavioural, affective and somatic symptoms associated with depression. Each item contains a statement that can be rated using the response options 'not at all', 'a little', 'some' or 'a lot', which are then converted to values between 0 and 3. Higher values indicate higher depressive symptomatology. For the analysis, the published cutoff of 16 was applied, which was determined in the family study for major depression [22].

\section{Externalising problems: Child Behavior Checklist (CBCL) scales}

In order to identify externalising behavioural problems, the externalising scale of the parentreported German version of the CBCL [1-3] was administered in the BELLA questionnaire for parents. The CBCL externalising problems scale refers to the past 6 months and includes two subscales, using 13 items to assess delinquent behaviour and 20 items for aggressive behaviour. The items contain statements about the behaviour of the young person, which can be rated as being 'not true', 'somewhat or sometimes true' or 'very true or often true'. Higher scores indicate a higher level of symptomatology. The scores from the parent-report were classified according to the manual into age- and sex-dependent categories which are based on the percentiles of the normative study.

\section{Attention deficit-/hyperactivity: Conners'scale and FBB-HKS}

Attention deficit-/hyperactivity disorders were identified by means of two different instruments. The 10- item Conners' Scale [16] assesses the occurrence of the most important symptoms of ADHD within the last month. It was applied during the telephone interview with the child as well as with the parent. The scores were classified by applying a cut-off score of 15 .

The German ADHD rating scale (FBB-HKS/ADHS) includes 20 items using the symptom criteria of both the ICD-10 and the DSM-IV, as well as additional criteria assessing symptom onset, symptom duration, pervasiveness and functional impairment. The items can be answered by parents and teachers [20]. This ADHD rating scale is part of the comprehensive diagnostic system for mental disorders in childhood and adolescence (DISYPS-KJ) [19]. Based on the manual, we calculated the mean overall severity score and transformed it to a scale from 0 to 3 . Scores of 2 or higher were interpreted as being an indicator of ADHD.

\section{Health-related quality of life: KINDL-R}

To measure HRQoL the generic KINDL-R questionnaire [35] was administered. The KINDL$\mathrm{R}$ questionnaire was specifically designed and validated for measuring HRQoL in children and adolescents. It consists of 24 Likert-scaled items referring to the past week, which assess the respondent's HRQoL in the following six dimensions: physical well-being, psychological well-being, self-esteem, family, friends, and everyday functioning (school). The KINDL-R 
proved to be highly reliable and sensitive to change. The scores on each KINDL-R subscale and the total score were transformed to values between 0 and 100 with higher values indicating better HRQoL.

\section{Substance use}

Problematic current alcohol consumption patterns (five to six glasses of beer or wine or two to four glasses of hard liquor or more on a regular basis), as well as drug abuse within the past year (repeatedly consuming marijuana, ecstasy, amphetamines, medication, or glue) was assessed from the self-reports of the 11-17 year olds.

\section{Suicide ideation/suicidal behaviour: Child Behavior Checklist (CBCL) items}

In order to obtain information on suicide ideation and suicidal behaviour within the past 6 months, two items from the German version of the CBCL [1] were employed ('I think about killing myself' and 'I deliberately harmed myself or attempted suicide'). These items were administered during the telephone interview with the response options 'not true', 'sometimes' and 'often/always'.

\section{Mental disorders and realised need for treatment}

Parents were asked for a current diagnosis by asking the question 'Does your child have a mental disorder (e.g. attention deficit-/hyperactivity disorder, depression, anxiety disorder, conduct disorder)?' with the response options 'yes' or 'no'. The realised need for treatment was assessed using one item from the children with special health care needs screener (CSHCN) [10] addressing the need for and use of treatment or counselling for emotional, developmental or behavioural problems ('Does your child have any kind of emotional, developmental or behavioural problem for which he or she needs or gets treatment or counselling?', response options 'yes' and 'no').

\section{Statistical analysis}

The statistical analyses are based on the sample data weighted to represent the age, gender, regional and citizenship structure of the German population (reference data 31 Dec 2004). The number of cases reported in the tables and in the text refers to weighted data and thus may deviate from the number of cases reported in the previous description of the sample. Percentages of mental health problems and $95 \%$ confidence intervals were calculated for all subgroups according to age and gender. To account for the clustered structure of the data (sample points) the SPSS complex samples procedure was used to calculate the percentages and confidence intervals of mental health problems. Student's t test was calculated to determine differences in HRQoL between children with and without identified mental health problems. Effect sizes (d) were quoted according to Cohen [15]. Effect sizes from 0.2 to 0.5 were designated as small, those between 0.51 and 0.8 were considered moderate and those over 0.81 large.

\section{Results}

Sample 
Of the 2,863 families participating in the study, $84 \%$ provided complete data including a telephone interview and a questionnaire from the parent as well as from the child if the latter was aged 11 or older. 1,133 families had children under the age of 11 . In $89 \%(n=1,009)$ of these families, a telephone interview as well as one questionnaire were obtained from the parent. In 120 cases (11\%), the telephone interview was conducted, but the questionnaire was not returned. Four families only returned the questionnaire, but did not take part in the telephone interview. Looking at the families with children aged 11 and older $(\mathrm{n}=1,730)$, in $81 \%(\mathrm{n}=1,395)$ of these families both telephone interviews and both questionnaires were obtained. In $12 \%$ of the families both telephone interviews were conducted, but the families failed to return the questionnaires. In the remaining families different combinations of missing data sources were present, e.g. either the questionnaire was not returned or the telephone interview did not take place. Regarding the sex distribution, the sample was well-balanced with $48.5 \%$ girls $(n=1,389)$ and $51.5 \%$ boys $(n=1,474)$. Also in terms of the age groups the sample shows a balanced distribution. A description of the sample is presented in Table 1.

Once the data had been weighted to be representative on a national level, the sample included $\mathrm{n}=950$ families with children aged 7-10 and $\mathrm{n}=1,913$ families with children aged 11-17. The weighted gender ratio was $48.8 \%$ girls $(n=1,396)$ versus $51.2 \%$ boys $(n=1,467)$.

\section{Frequency of mental health problems and prevalence estimates}

Tables 2, 3 and 4 show frequency rates of overall and specific mental health problems, separately for ages and gender, based on the published cut-off scores in the first column. The second column indicates the prevalence of cases who meet cut-off scores as well as the impairment criteria (SDQ impact). For these children, identified as cases, the percentage of children needing or receiving treatment according to the parent's report is given in column three.

As shown in Table 2, the prevalence of children with an abnormal extent of symptoms of overall mental health problems as well as reported impairment is $6.3 \%$. Boys $(8.8 \%)$ are affected approximately twice as much as girls (3.7\%). However, when only symptom scores are taken into account, and present impairment is not taken into consideration, the overall prevalence estimate increases from 6.3 to $8.6 \%$.

Among children aged 11 to 17, the prevalence rate of impairing mental health problems is $4.9 \%$, with boys $(5.7 \%)$ again being affected more frequently than girls $(4.0 \%)$. However, the difference between the sexes is smaller in this age group than in the younger children. If only abnormal SDQ scores are considered, the estimate increases from 4.9 to $6.6 \%$.

Regarding the specific problems of children aged 7-10 (Table 3), the frequency of symptoms based on published cut-offs ranges between $4.5 \%$ (attention deficit-/hyperactivity disorder) and $15.5 \%$ (conduct disorder). The percentage of cases with high symptom scores as well as reported impairment (column 2) shows that all prevalence estimates are reduced considerably if the criterion of given impairment is applied, with the largest decrease in the prevalence of anxiety (from 14.3 to $6.3 \%$ ). The final prevalence estimates for specific mental health problems thus range from $3.9 \%$ (ADHD) to $8.7 \%$ (conduct disorder). Furthermore, Table 3 shows that only between 26.3 and $37.5 \%$ of the children with specific mental health problems and impairment are considered to be in need of treatment. A noticeable difference between boys and girls is found, with $32.9-58.2 \%$ of the former and only $14.3-21.2 \%$ of the latter being treated. Even though confidence intervals are large (due to the small case numbers). 
This tendency is consistent across all specific mental health conditions and most pronounced regarding anxiety and depression.

Regarding specific mental health problems in children aged 11-17 (Table 4), the frequency of problems based on published cut-off scores ranges between 2.3\% (ADHS) and 14.2\% (conduct disorder). Similar to the overall estimate, when the criterion of impairment is included in the case definition, prevalence estimates of all specific mental health problems (except for ADHD) are reduced, whereby the rates of depression and anxiety are cut by approximately half. The final prevalence estimates range from $2.2 \%$ (ADHD) to $9.7 \%$ (conduct disorder). The incidence of children with disorders and impairments who are considered to be in need of treatment is slightly higher $(25.8-41.9 \%)$ in this age group. However, due to the large confidence intervals no significant trend can be identified. Similarly, sex differences regarding treatment needs cannot be taken to be proven.

For those children where parents reported symptoms as well as impairment the percentage of reported diagnosis was higher than in children where only symptoms of overall mental health problems were reported. Regarding specific mental health problems in the younger age group, parents of children screening positive for depression (34.5\%) reported most frequently an existing diagnosis. In the older age group, the highest rate of parent-reported existing diagnosis was found for children who screened positive for ADHD (49.0\%) (data not shown).

Overall, $14.5 \%$ of the children and adolescents aged 7-17 fulfilled the criteria for at least one specific mental health problem associated with impairment, or had an overall mental health problem indicated by an abnormal SDQ score plus associated impairment. Within this group of affected children, $5.8 \%$ displayed one mental health problem alone, whereas $8.7 \%$ of children displayed two or more mental health problems.

Table 5 presents prevalence rates of self-reported problematic behaviour for children and adolescents aged 11-17 years. High alcohol consumption was reported by $6.1 \%$ of adolescents, with a considerable difference between the sexes $(2.5 \%$ in girls vs. $9.5 \%$ in boys). Similarly, drug use was reported by more boys (4.8\%) than girls $(2.1 \%)$. Suicidal behaviour and suicide ideation was reported more frequently by girls (3.7 and 5.2\%, respectively) than by boys ( 2.0 and $2.5 \%$, respectively). However, only approximately half of these children were also impaired according to their parents' reports.

Based on the parents' estimation, the lowest numbers for children needing or receiving treatment $(15.9 \%)$ were found in children displaying problematic alcohol consumption. The highest percentage of children needing or receiving treatment was found in users of illegal drugs $(36.4 \%)$. However, only approximately $29 \%$ of the children reporting suicidal behaviour or suicidal ideation were considered to need or receive treatment.

Regarding the consequences of mental health problems, HRQoL was found to be substantially reduced for the children, who experienced an overall mental health problem or an impairing specific mental health problem compared with those not meeting these criteria (Fig. 1). The magnitude of the impact on HRQoL ranged from $\mathrm{d}=0.57$ (moderate effect) for physical wellbeing to $\mathrm{d}=1.33$ (large effect) in the total score. 


\section{Discussion}

It can be seen that the frequency of symptoms of overall mental health problems (SDQ symptom scores) corresponds to the results reported for the KiGGS main survey [28], supporting the representativeness of the sub-sample under examination for the entire KiGGS sample. In order to report conservative prevalence estimates, this paper only considers children with 'abnormal' SDQ scores and additional impairment as being actual cases. Therefore, the reported results for overall mental health problems are lower than some estimates published previously. In general, the reported results, which are based on the published cutoffs, confirm the findings of other national and international studies $[8,9,17$, 29]. However, unlike other German and international studies which report higher prevalence rates in samples of older children and adolescents [8,23], our findings suggest a small decrease in overall mental health problems in the older age group. This decrease was found in almost all specific conditions except for depression, with the most pronounced decrease in ADHD. These findings may be due to several underlying causes. First, we did not include younger children below the age of 7 in our sample, for whom smaller rates have previously been reported [8]. An even more important reason may be that only the parents' reports were considered in this analysis, which might be less sensitive regarding the mental health problems of older adolescents. Especially regarding internalising disorders, the parents' basis of information is more restricted whereas externalising problems are more obvious [18]. Our results also correspond to the findings from the UK normative study of the SDQ parent form: no differences or even marginal decreases in the overall symptom score and the specific subscales of the SDQ instrument were found between the ages of 5-10 years and 11-15 years [32].

Comparing the prevalence rates of children having impairing mental health problems with the number of children meeting symptom criteria shows that the latter are not necessarily impaired by their 'condition'. On the other hand, the substantial proportion of children fulfilling symptom plus impairment criteria illustrates the burden that comes with the observed mental health conditions.

The analysis of the treatment situation of children and adolescents showed that consistently less than half of the children and adolescents with identified mental health problems received treatment or were recognised by their parents as being in need of treatment. In the younger age group, we found evidence of sex-specific differences, with girls being consistently considered to be in less need of treatment or receiving less treatment than boys. The fact that especially younger girls with emotional problems (anxiety and depression) constitute a group with high risk for unrecognised mental problems hints at gender-specific prejudices as a potential reason: it is likely that parents still expect their female children to be more sensible and calmer than boys and therefore do not recognise manifest health care needs. This interpretation is supported by the fact that parent-reported rates of depression do not display gender differences whereas self-reported data do (data not shown).

It must be kept in mind that the applied item from the CSHCN screener does not only ask about the child receiving treatment, but also about the necessity of treatment. Parents of affected children who answer 'no' to this question unfortunately do not even recognise their children as being in need of support and health care. This is especially noticeable regarding the observed large impact that the identified mental health problems have on HRQoL. 
Our results partly reflect the poor awareness of treatment needs and therefore emphasise the importance of adequate diagnoses by professionals (physicians, psychologists or similar) in order to assign the appropriate treatment to the affected youths.

On the other hand, the cut-off criteria used in some screening instruments (e.g. SCARED) might be viewed as being insufficiently validated and too liberal, with respondents being too easily classified as mentally ill. Especially available screening instruments for specific mental health problems have often not been applied in population samples before, or else they have not been compared with a reliable gold standard. The published measures of sensitivity and specificity are therefore of limited generalisability. However, insufficient specificity must be assumed to result in reduced positive predictive power, indicating that not all of the children identified are true cases.

The percentage of parent-reported present diagnoses was low. The highest probability of a reported diagnosis was found in children exceeding the cut-off scores and in addition displaying impairment. Compared with children exceeding published cut-off scores without being impaired, their rates of reported diagnosis were increased. This result can be interpreted in two ways: on the one hand, perceived impairment may contribute to the probability of a child being diagnosed; on the other hand, the application of impairment criteria when screening for mental health problems may enhance the validity of the assessment.

The validity of the assessment is especially important when determining prevalence rates of mental health problems, since it is connected with a variety of methodological challenges that also have to be discussed regarding the results presented. Even though the findings are plausible in the context of previous research, one has to keep in mind that they are highly dependent on the applied screening instrument and which cut-off criteria are used. This became especially apparent in the two ADHD instruments under investigation, which led to widely different prevalence estimates, whereby the Conners' Scale resulted in considerably higher prevalence estimates than the FBBHKS. Since the FBB-HKS is designed to operationalise the DSM-IV criteria and mimics the actual process of clinical diagnosis, it might be assumed that it is stricter regarding case definition and that its results are closer to a clinical assessment. Yet, due to the absence of a clinical diagnosis, it was not possible to directly test for the diagnostic quality of the two instruments. In general, the construction of efficient screening instruments that operationalise the criteria of the classification systems DSM-IV or ICD-10, such as the FBB-HKS [20], and can be applied in large surveys, seems to be a promising approach. However, few of the instruments available meet such requirements.

A major strength of the present study is that it takes criteria of impairment into account and can separate the presence and severity of the symptoms from the associated impact. As discussed above, prevalence rates are reduced substantially if impairment criteria are taken into account. For the SDQ administered in this study, Goodman et al. [25-27] have shown that even the short impact supplement on its own has a higher diagnostic quality (regarding discrimination between respondents with and without a psychiatric diagnosis) when screening for a psychiatric disorder than the symptom scales of the SDQ. The crucial role of perceived impairment is also mirrored by the WHO's International Classification of Functioning, Disability and Health (ICF) [42] and the diagnostic manuals ICD-10 and the DSM-IV [4, 41], which also consider social disabilities (ICD-10) or the global assessment of functioning (DSM-IV).

In our study we decided to use a generic impact score relating to emotional and social problems, but also concentration and behaviour. Although the impact of specific symptoms 
and disorders cannot be determined, the generic impairment can be used to estimate comparable prevalence rates of mental health problems in children and adolescents.

We decided to focus on parent-reported data since this approach also facilitated the comparability of prevalence rates across the age groups. Thus, this advantage goes along with the problematic nature of parent-reported data that was mentioned above. As illustrated by the results on suicidal tendencies, impairment in particular may be less obvious to a proxy: The fact that fewer than half of the children and adolescents with suicidal tendencies are reported to be impaired makes the limitations of this parent-reported information obvious.

Another limitation of the results presented is the large confidence intervals regarding the treatment needs. However, this problem is unavoidable when it comes to determining properties of small subgroups, and in view of the importance of this issue the publication of this kind of data seems justifiable.

To sum up, the present paper found noticeable rates of mental health problems in children and adolescents and pointed out the importance of applying additional measures of impairment. It became apparent that only few of those children and adolescents meeting symptom criteria as well as displaying impairment are diagnosed by a health professional or are recognised to be in need of treatment. Since recognition of treatment needs seems to depend on the externalising nature of the problems and might be partly influenced by gender-specific prejudices, educating parents about the signs and symptoms of such mental problems becomes increasingly important.

Furthermore, determining those who are in need of an adequate preventive or treatment program requires efficient, sensitive and valid screening instruments whose development still needs to be promoted.
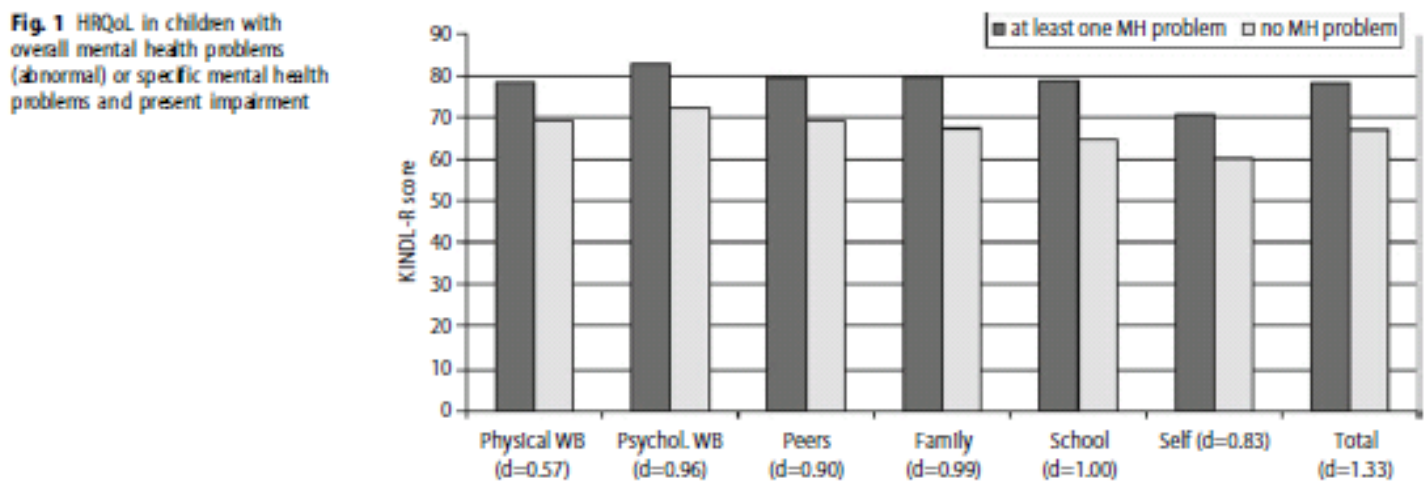
Table 1 Sample desaiption, Gaman BELA sample; age ange 7-17 yeas $(n=2863)$

\begin{tabular}{|c|c|c|}
\hline & Unweighted & Weighted \\
\hline \multicolumn{3}{|l|}{ Sex } \\
\hline Male & $51.5 \%(1,474)$ & $512 \%(1,467)$ \\
\hline Fende & $48.5 \%(1,389)$ & $488 \%(1,396)$ \\
\hline \multicolumn{3}{|l|}{ Region } \\
\hline $\begin{array}{l}\text { Former German Democratic } \\
\text { Republicic }\end{array}$ & $363 \%(1,040)$ & $17.1 \%$ (489) \\
\hline $\begin{array}{l}\text { Former federal Republic of } \\
\text { Germany }\end{array}$ & $63.7 \%(1,823)$ & $829 \%(2,374)$ \\
\hline \multicolumn{3}{|l|}{ Age } \\
\hline $7-10$ & $39.6 \%(1,133)$ & $332 \%(950)$ \\
\hline $11-13$ & $27.1 \%(777)$ & $26.1 \%(746)$ \\
\hline $14-17$ & $33.3 \%$ (953) & $408 \%(1,167)$ \\
\hline \multicolumn{3}{|l|}{ Migation } \\
\hline Yes & $9.8 \%(281)$ & $121 \%(347)$ \\
\hline No & $90.096(2,578)$ & $878 \%(2,513)$ \\
\hline No information & $0.1 \%(4)$ & $0.1 \%(3)$ \\
\hline \multicolumn{3}{|l|}{ Famillal constelation } \\
\hline Wth biological parents & $75.5 \%(2,162)$ & $766 \%(2,192)$ \\
\hline Single prent & $12.996(369)$ & $13.1 \%(375)$ \\
\hline $\begin{array}{l}\text { One biological parent plus } \\
\text { new pantner }\end{array}$ & $10096(286)$ & $90 \%(256)$ \\
\hline Others & $0.9 \%(27)$ & $0.6 \%(18)$ \\
\hline No information & $0.7 \%(19)$ & $08 \%(22)$ \\
\hline \multicolumn{3}{|l|}{ Socioec anomic status" } \\
\hline Low & $24.8 \%(710)$ & $250 \%(716)$ \\
\hline Medium & $47.6 \%(1,362)$ & $46.5 \%(1,330)$ \\
\hline High & $268(767)$ & $276 \%(789)$ \\
\hline No information & $0.8 \%(24)$ & $09 \%(27)$ \\
\hline
\end{tabular}

Due to rounding some of the percentages do not add to 100

"According to Winkla and Stoberiberg [10]

Table 2 Fequency of pasentreponted overal mental heati problems in dilitien and adolescents $(n=2833)$

\begin{tabular}{|c|c|c|c|}
\hline & $\begin{array}{l}\text { Finquency of high } \\
\text { symptam scoes based } \\
\text { an pubilished cut-off }\end{array}$ & $\begin{array}{l}\text { Prevalence of dilden } \\
\text { with syenptoms and } \\
\text { imparment }\end{array}$ & $\begin{array}{l}\text { Rectiving of } \\
\text { needing } \\
\text { treatment" }\end{array}$ \\
\hline \multicolumn{4}{|c|}{ Ments heelth problems (SDQ abnoms) } \\
\hline Total $(7-17$ years) & $72 \%[6.1-8.5]$ & $5.69[4.5-69]$ & $40.2 \%[30.4-50.9]$ \\
\hline Total ( $7-10$ yeas $)$ & $8.69 \%[6.8-10.8]$ & $6.396[4.7-8.4]$ & $34.496[21.1-50.7]$ \\
\hline Gils & $5.896[3.7-8.9]$ & $3.7 \%[1.9-7.0]$ & $13.196[1.7-56.5]$ \\
\hline Boys & $11.396[8.6-14.6]$ & $8.8 \%[6.4-11.9]$ & $43.196[25.7-62.4]$ \\
\hline Total (11-17 yeas) & $6.696[5.3-8.1]$ & $4.906[3.80-5.9]$ & $45.895[320-60.3]$ \\
\hline Gits & $5.3 \%[3.7-7.5]$ & $4.0 \%[2.61-5.4]$ & $46.996[25.4-69.7]$ \\
\hline Boys & $7.806[60-10.0]$ & $5.796[4.09-7.3]$ & $45.196[27.0-64.5]$ \\
\hline \multicolumn{4}{|c|}{ Mentd heilth problens (SDQ bouderine of abnormal) } \\
\hline Total $(7-17$ years) & $13.3 \%[11.8-15.0]$ & & \\
\hline Total $(7-10$ yeas $)$ & $16.1 \%[13.5-18.9]$ & & \\
\hline Gils & $11.4 \%[8.5-15.0]$ & & \\
\hline Boys & $20.496[16.7-24.8]$ & & \\
\hline Total (11-17 yeas) & $122 \%$ [103-14.3] & & \\
\hline Gils & $9.5 \%[73-12.2]$ & & \\
\hline Boys & $14.8 \%[123-17.7]$ & & \\
\hline
\end{tabular}

*Parent-reponed need for of prodsion of treatment

\begin{tabular}{|c|c|c|c|}
\hline & $\begin{array}{l}\text { Frequency of high } \\
\text { symgtam scoues based } \\
\text { on pudiliched cofl-off }\end{array}$ & $\begin{array}{l}\text { Prealence of dildren } \\
\text { with symptoms and } \\
\text { imparment }\end{array}$ & $\begin{array}{l}\text { Reredving of } \\
\text { needing } \\
\text { treatment" }\end{array}$ \\
\hline Depression (CE- DC $\geq 16$ ) & $10.7 \%$ [8.8-13.1] & $5.696[40-7.6]$ & $37.5 \%$ [23.5-53.9] \\
\hline Gins & $10.096[7.1-14.0]$ & $5.606[3.4-9.2]$ & $17.896[5.0-0.1]$ \\
\hline Bogs & $11.496[8.6-14.9]$ & $5.5 \%[3.7-7.9]$ & $58.2 \%[35.6-77.8]$ \\
\hline Anxety (sCarED-5 $\geq 3$ ) & $14.3 \%[12.1-16.8]$ & $6.39[4.7-8.5]$ & $26.3 \%[14.9-42.1]$ \\
\hline Gins & $16.5 \%[13.1-20.5]$ & $7.5 \%[4.9-113]$ & $14.3 \%[1.3-37.9]$ \\
\hline Bogs & $12.3 \%[9.6-15.6]$ & $5.2 \%[3.4-7.7]$ & $43.8 \%[222-68.1]$ \\
\hline AOHS (FBB-HNS $\geq 2)$ & $4.5 \%[3.0-6.6]$ & $3.996[2.5-5.9]$ & $329 \%[16.2-55.3]$ \\
\hline Girs & $26 \%[1.0-63]$ & $22 \%[0.8-6.0]$ & $21.2 \%[1.5-83.0]$ \\
\hline Bogs & $6.2 \%[1<2-9.2]$ & $5.5 \%[(3.6-8.2]$ & $37.466[17,2-63,3]$ \\
\hline ADHS (Connes $\geq 15$ ) & $10.396[8.3-12.8]$ & $6.4 \%[4.8-8.6]$ & $32.46[20.1-47.8]$ \\
\hline Gins & $7.596[5.2-10.6]$ & $4.46[2.7-7.0]$ & $260006.4-5.5]$ \\
\hline Bogs & $13.1 \%[10.1-16.7]$ & $8.46[6.0-11.6]$ & 37.006 [20.9-56.6] \\
\hline Conduct disordet (CBC) & $15.5 \%[13.0-18.3]$ & $8.7 \%[6.7-11.1]$ & $27.006[16.9-40.3]$ \\
\hline Girs & $14.8 \%[11.8-18.4]$ & $6.796[4.4-10.1]$ & $17.7 \%[5.8-0.9]$ \\
\hline Bogs & $16.19[1126-20.4]$ & $10.5 \%[7.9-13.9]$ & $32.99 \%[19.2-50.2]$ \\
\hline
\end{tabular}

"Parent-reponed need for of prodilon of teatment
Table 3 frequency of pasentreponed specific mental heath problems in dillden aged 7-18 $(n=985)$ 
Table 4 frequency of parentrepoited spectic mental heath problems in

\begin{tabular}{|c|c|c|c|}
\hline & $\begin{array}{l}\text { frequency of hight } \\
\text { symptom scoes baed } \\
\text { an pultilhed cul-off }\end{array}$ & $\begin{array}{l}\text { Prevalence of dildren } \\
\text { with symptams and } \\
\text { imparment }\end{array}$ & $\begin{array}{l}\text { Recetving of } \\
\text { neding } \\
\text { trettment" }\end{array}$ \\
\hline Depression (CE- $D C \geq 16$ ) & $11.1 \%[9.3-13.1]$ & $4996[3.7-6.5]$ & $30.2 \%[18.6-4.8]$ \\
\hline Gints & $11.5 \%[9.0-14.5]$ & $4.60 \%[3.2-6.4]$ & $22806[10.9-41.5]$ \\
\hline Bogs & $10.7 \%[3.5-13.3]$ & $53 \%[3.5-7.9]$ & $36.6 \%[19.0-58.7]$ \\
\hline Anxety (SCARED-5 $\geq 3$ ) & $9.996[8.4-11.6]$ & $4.096[3.0-5.4]$ & $41.9 \%[26.7-58.7]$ \\
\hline Girk & $11.396[9.1-140]$ & $4.296[28-6.1]$ & $41.2 \%[233-61.7]$ \\
\hline Bogs & $8.5 \%[6.7-10.8]$ & $3.896[2.5-5.9]$ & $42.6 \% 6[21.2-67.1]$ \\
\hline ADHS (FBB-HKS $\geq 2]$ & $2.396[1.6-3.4]$ & $2206[1.5-32]$ & $25.8 \%[11.1-49.2]$ \\
\hline Girs & $1.6 \%[0.7-3.2\}$ & $1.5 \%[0.7-3.2]$ & $36.2 \%[6.2-8.9]$ \\
\hline Bogs & $3.196[20-4.9]$ & $2.896[1.7-4.5]$ & $19.8 \%[6.8-15.2]$ \\
\hline AOH'́s (Connes $\geq 15$ ) & $7.90 \%[6.4-9.7]$ & $4996[3.8-6.4]$ & $39.7 \%[27.8-52.9]$ \\
\hline Girs & $6.73[(1.8-9.2)$ & $4.006[26-6.1]$ & $38.9 \%(20.7-60.9]$ \\
\hline Bogs & $9.0 \% 6[7.1-11.3]$ & $5.8 \%[4.2-8.1]$ & $40.2 \%[24.7-57.8]$ \\
\hline Conduat dsooder (KBCU) & $14.296[121-16.5]$ & $9.7 \%[7.9-11.7]$ & $27.8 \%[18.9-38.8]$ \\
\hline Girk & $13.3 \%[10.7-16.4]$ & $8.496[6.3-11.2]$ & $33.4 \%[200-50.0]$ \\
\hline Bogs & $15.0 \%[122-18.4]$ & $1096[84-140]$ & $23.3 \%[13.1-38.0]$ \\
\hline
\end{tabular}

"Parent-reponed need for or prodsion of treatment

Table 5 Seffrepoted prealence ates for substance abuse and suidde ideaton/behiviour (impairment reported by parents) in dialiren aged 11-17 ( $n=1,861$ )

\begin{tabular}{|c|c|c|c|}
\hline & $\begin{array}{l}\text { Prevalence } \\
\text { of behavour }\end{array}$ & $\begin{array}{l}\text { Oildren with } \\
\text { behavour and } \\
\text { impaiment }\end{array}$ & $\begin{array}{l}\text { Recelving of } \\
\text { needing } \\
\text { treatment" }\end{array}$ \\
\hline \multicolumn{4}{|c|}{ High akohol consumption } \\
\hline \multicolumn{4}{|c|}{ (5.6 glasses of beed/wine or 24 glasses of hard liquor of more) } \\
\hline Total & $6.1 \%[4.7-7.8]$ & $1.6 \%[09-28]$ & $15.9 \%[2.7-55.9]$ \\
\hline Gris & $2.5 \%[1.6-4.0]$ & $0.5 \%[01-2.4]$ & $83.3 \%[10.0-1000]$ \\
\hline Boys & $9.5 \%[7.2-123]$ & $26 \%[14-4.8]$ & $4.996[0.5-37.0]$ \\
\hline \multicolumn{4}{|c|}{$\begin{array}{l}\text { Repested drug use } \\
\text { (marifuana/ecstasydamphetamines/medication/glue) }\end{array}$} \\
\hline Total & $3.5 \%$ [2.1-3.9] & $1.2 \%[07-2.1]$ & $36.496[12.2-70.3]$ \\
\hline Gris & $21 \%[1.2-3.6]$ & $0.7 \%[03-1.8]$ & $49.19[1.9-9.8]$ \\
\hline Boys & $4.896[3.2-6.9]$ & $1.6 \%[08-33]$ & $31.19[6.4-7.7]$ \\
\hline \multicolumn{4}{|c|}{ Sukidal ideation } \\
\hline \multicolumn{4}{|c|}{ (I think about kiling myelif) } \\
\hline Total & $3.8 \%[2.9-5.1]$ & $1.4 \%[09-22]$ & $28.7 \%[11.2-56.2]$ \\
\hline Grls & $5.296[3.7-7.4]$ & $1.7 \%[10-2.9]$ & $32.6 \%[10.6-66.3]$ \\
\hline Boys & $25 \%[1.5-4.1]$ & $1.29[06-26]$ & $222 \%[20-79.6]$ \\
\hline \multicolumn{4}{|c|}{ Sukidal behavour } \\
\hline \multicolumn{4}{|c|}{ I delberately hamed mysedf or attempted suidde' } \\
\hline Total & $2996[2.5-4.7]$ & $1.1 \%[06-1.9]$ & $28.09 \%[3.4-62]$ \\
\hline Gris & $3.7 \%[2.5-5.6]$ & $1.6 \%[0.8-29]$ & $28.9 \%[7.8-66.1]$ \\
\hline Boys & $2096[12-3.3]$ & $0.7 \%[0.2-1.9]$ & $23.9 \%[0.2-9.3]$ \\
\hline
\end{tabular}

*Parent-eported need for or provision of treatment

\section{References}

1. Arbeitsgruppe Deutsche Child Behavior Checklist (1998) Elternfragebogen über das Verhalten von Kindern und Jugendlichen; deutsche Bearbeitung der Child Behavior Checklist (CBCL/4-18). Einführung und Anleitung zur Handauswertung, 2. Auflage mit deutschen Normen. Arbeitsgruppe Kinder-, Jugend- und Familiendiagnostik, Köln

2. Achenbach TM (1991) Manual for the Child Behavior Checklist/4-18 and 1991 Profile. University of Vermont, Department of Psychiatry, Burlington

3. Achenbach TM (1991) Manual for the Youth Self-Report and 1991 Profile. University of Vermont, Department of Psychiatry, Burlington

4. American Psychiatric Association (2000) Diagnostic and statistical manual of mental disordersDSM-IV-TR, 4th edn. APA, Washington, DC

5. Antonovsky A (1987) Unraveling the mystery of health. Bass, San Francisco

6. Bastine R (1998) Klinische Psychologie. Band 1. Grundlegung der Allgemeinen Klinischen Psychologie, Kohlhammer, Stuttgart 
7. Barkmann C, Schulte-Markwort M (2002) Wie gesund sind die Seelen unserer Kinder? Zur Epidemiologie von Erlebens- und Verhaltenssauffälligkeiten bei 4-18-jährigen in Deutschland. XXVII. Kongress der Deutschen Gesellschaft für Kinder- und Jugendpsychiatrie und Psychotherapie, 3-6 April, Berlin

8. Barkmann C, Schulte-Markwort M (2004) Prävalenz psychischer Auffälligkeiten bei Kindern und Jugendlichen in Deutschland - ein systematischer Literaturüberblick. Psychiatr Prax 31:1-10

9. Belfer ML (2008) Child and adolescent mental disorders: the magnitude of the problem across the globe. J Child Psychol Psychiatry 49:226-236

10. Bethell C, Read D, Stein RE, Blumberg SJ, Wells N, Newacheck PW (2002) Identifying children with special health care needs: development and evaluation of a short screening instrument. Ambul Pediatr 2:38-48

11. Bettge S, Ravens-Sieberer U, Wietzker A, Hölling H (2002) Ein Methodenvergleich der Child Behavior Checklist und des Strengths and Difficulties Questionnaire. Gesundheitswesen 64:119-124

12. Bettge S, Ravens-Sieberer U (2003) Schutzfaktoren für die psychische Gesundheit von Kindern und Jugendlichen- empirische Ergebnisse zur Validierung eines Konzepts. Gesundheitswesen 65:167172

13. Birmaher B, Brent DA, Chiappetta L, Bridge J, Monga S, Baugher M (1999) psychometric properties of the screen for child anxiety related emotional disorders (SCARED): a replication study. $\mathrm{J}$ Am Acad Child Adolesc Psychiatry 38:1230-1236

14. Birmaher B, Khetarpal S, Brent D, Cully M, Balach L, Kaufman J, Neer SM (1997) The screen for child anxiety related emotional disorders (SCARED): scale construction and psychometric characteristics. J Am Acad Child Adolesc Psychiatry 36:545-553

15. Cohen J (1988) Statistical power analysis for the behavioural sciences, 2nd edn. Lawrence Erlbaum Associates, Inc, Hillsdale

16. Conners CK (1973) Rating scales for use in drug studies with children. Pharmacotherapy of children [Special issue]. Psychopharmacol Bull 9:24-29

17. Costello EJ, Egger H, Angold A (2005) 10-year research update review: the epidemiology of child and adolescent psychiatric disorders: I. Methods and public health burden. J Am Acad Child Adolesc Psychiatry 44:972-986

18. Döpfner M, Plück J, Berner W, Fegert JM, Huss M, Lenz K, Schmeck K, Lehmkuhl U, Poustka F, Lehmkuhl G (1997) Psychische Auffälligkeiten von Kindern und Jugendlichen in Deutschland Ergebnisse einer repräsentativen Studie: Methodik, Alters-, Geschlechts- und Beurteilereffekte. Z Kinder Jugendpsychiatr Psychother 25:218-233

19. Döpfner M, Lehmkuhl G (2000) Diagnostik-System für psychische Störungen im Kindes- und Jugendalter nach ICD-10 und DSM-IV (DISYPS-KJ), 2nd edn. Verlag Hans Huber, Bern

20. Döpfner M, Steinhausen H-C, Coghill D, Dalsgaard S, Poole L, Ralston SJ, Rothenberger A, the ADORE study group (2006) Cross-cultural reliability and validity of ADHD assessed by the ADHD Rating Scale in a pan-European study. Eur Child Adolesc Psychiatry 15(Suppl1):46-55

21. Faulstich ME, Carey MP, Ruggiero L, Enyart P, Gresham F (1986) Assessment of depression in childhood and adolescence: an evaluation of the Center for Epidemiological Studies Depression Scale for Children (CESDC). Am J Psychiatry 143:1024-1027

22. Fendrich M, Weissman MM, Warner V (1990) Screening for depressive disorder in children and adolescents: validating the Center for Epidemiologic Studies Depression Scale for Children. Am J Epidemiol 131:538-551

23. Ford T, Goodman R, Meltzer H (2003) The British child and adolescent mental health survey 1999: The prevalence of DSM-IV isorders. J Am Acad Child Adolesc Psychiatry 42(10):1203-1211 24. Goodman R (1997) The strengths and difficulties questionnaire: a research note. J Child Psychol Psychiatry 38:581-586

25. Goodman R (1999) The extended version of the strengths and difficulties questionnaire as a guide to child psychiatric caseness and consequent burden. J Child Psychol Psychiatry 40:791-799

26. Goodman R, Ford T, Simmons H, Gatward R, Meltzer H (2000) Using the strengths and difficulties questionnaire (SDQ) to screen for child psychiatric disorders in a community sample. $\mathrm{Br} \mathrm{J}$ Psychiatry 177:534-539

27. Goodman R, Renfrew D, Mullick M (2000) Predicting type of psychiatric disorder from strengths and difficulties questionnaire (SDQ) scores in child mental health clinics in London and Dhaka. Eur Child Adolesc Psychiatry 9:129-134 
28. Hölling H, Erhart M, Ravens-Sieberer U, Schlack R (2007) Verhaltensauffälligkeiten bei Kindern und Jugendlichen. Erste Ergebnisse aus dem Kinder- und Jugendgesundheitssurvey (KiGGS).

[Behavioural problems in children and adolescents. First results from the German Health Interview and Examination Survey for Children and Adolescents (KiGGS)]. Bundesgesundheitsbl

Gesundheitsforsch Gesundheitsschutz 50:784-793

29. Ihle W, Esser G (2002) Epidemiologie psychischer Störungen im Kindes- und Jugendalter.

Prävalenz, Verlauf, Komorbidität und Geschlechtsunterschiede. Psychol Rundsch 53:159-169

30. Kamtsiuris P, Lange M, Schaffrath Rosario A (2007) Der Kinder- und Jugendgesundheitssurvey

(KiGGS): Stichprobendesign, Response und Nonresponse- Analyse. Bundesgesundheitsbl -

Gesundheitsforsch - Gesundheitsschutz 50:547-555

31. Masten AS, Hubbard JJ, Gest SD, Tellegen A, Garmezy N, Ramirez M (1999) Competence in the context of adversity: Pathways to resilience and maladaptation from childhood to late adolescence.

Dev Psychopathol 11:143-169

32. Meltzer H, Gatward R, Goodman R, Ford T (2000) Mental health of children and adolescents in Great Britain. Stationary Office, London

33. Palfrey JS, Tonniges TF, Green M, Richmond J (2005) Introduction: addressing the millennial morbidity - the context of community. Pediatrics 115:1121-1123

34. Patel V, Flisher AJ, Hetrick S, McGorry P (2007) Mental health of young people: a global publichealth challenge. Lancet 369:1302-1313

35. Ravens-Sieberer U (2003) Der Kindl-R Fragebogen zur Erfassung der gesundheitsbezogenen Lebensqualität bei Kindern und Jugendlichen - Revidierte Form. In: Schumacher JKA, Brähler E (eds) Diagnostische Verfahren zu Lebensqualität und Wohlbefinden. Göttingen, Hogrefe, pp 184-188 36. Ravens-Sieberer U, Kurth B-M, KiGGS study group, BELLA study group (2008) The mental health module (BELLA study) within the German Health Interview and Examination Survey of Children and Adolescents (KiGGS): study design and methods. Eur Child Adolesc Psychiatry 17(Suppl1):10-21

37. Ravens-Sieberer U, Wille N, Bettge S, Erhart M (2007) Psychische Gesundheit von Kindern und Jugendlichen in Deutschland. Ergebnisse aus der BELLA-Studie im Kinder- und

Jugendgesundheitssurvey (KiGGS). [Mental health of children and adolescents in Germany. Results from the BELLA study within the German Health Interview and Examination Survey for Children and Adolescents (KiGGS)]. Bundesgesundheitsbl Gesundheitsforsch Gesundheitsschutz 50:871-878 38. Roberts RE, Attkisson CC, Rosenblatt A (1998) Prevalence of psychopathology among children and adolescents. Am J Psychiatry 155:715-725

39. Weissman MM, Orvaschel H, Padian N (1980) Children's symptom and social functioning selfreport scales. Comparison of mothers' and children's reports. J Nerv Ment Dis 168:736-740

40. Winkler J, Stolzenberg H (1999) Der Sozialschichtindex im Bundes-Gesundheitssurvey.

Gesundheitswesen 61(Sonderheft 2):S178-S183

41. World Health Organization (1993) The ICD-10 classification of mental and behavioural disorders: multiaxial presentation. WHO, Geneva

42. World Health Organization (2001) International classification of functioning, disability and health (ICF). WHO, Geneva

43. World Health Organization (2001) The World health report. Mental health: new understanding, new hope. Geneva, WHO. Available at: http://www.who.int/whr/2001/en/whr01 en.pdf Accessed August 2008 